\title{
Late potentials as predictors of risk after thrombolytic treatment?
}

Günter Breithardt, Martin Borggrefe, Ulrich Karbenn

Late potentials represent low amplitude fractionated electrical activity and they appear at the end of or after the QRS complex. They can be recorded directly by catheter mapping or intraoperative endocardial and epicardial mapping ${ }^{1-3}$ or indirectly from the body surface by "high-resolution electrocardiography"4-7 after myocardial infarction in patients with sustained ventricular tachycardia. These potentials originate from asynchronous electrical activity in bundles of surviving muscle, mostly at the border of a myocardial infarction. These surviving muscle bundles are separated by fibrous tissue that can form isolating boundaries between them. ${ }^{89}$ The low amplitude of these signals is probably the result of the large amount of connective tissue and few surviving muscle fibres beneath the electrode. ${ }^{8}$ They are considered as markers for an "arrhythmogenic substrate" that may become the site for re-entry. ${ }^{10}$ However, not all sites showing late potentials are arrhythmogenic; occasionally they are non-specific markers of local fibrosis. ${ }^{11}$

Late potentials have rarely been seen in patients with normal left ventricular function. ${ }^{4-7}$ But they were found in $90 \%$ of patients with ventricular tachycardia or ventricular fibrillation after previous myocardial infarction. ${ }^{6}$ Late potentials were much less common in patients with previous ventricular fibrillation than in patients with sustained uniform ventricular tachycardia. ${ }^{6}$ The longer the duration of late potentials the faster was the rate of ventricular tachycardia. Late potentials were most common in patients with left ventricular aneurysms caused by coronary artery disease and in patients with other abnormalities of left ventricular contraction. ${ }^{12}$ Late potentials were more common in patients with inducible ventricular tachycardia. ${ }^{13}$

Late potentials are strong predictors of arrhythmic events after myocardial infarction. ${ }^{7}$ This was convincingly shown in more than 2000 survivors of myocardial infarction. The presence. of late potentials during recovery from myocardial infarction (detected by the use of high resolution electrocardiography) correlated with the subsequent occurrence of sustained uniform ventricular tachycardia or death from arrhythmia or both.

Clinical reports that showed a correlation between the absence of late potentials after myocardial infarction and the success of thrombolytic treatment are important because they indicate that effective thrombolytic treatment can prevent the development of an abnormal electrophysiological milieu after myocardial infarction. ${ }^{14-16}$

Eldar et al reported on the effect of thrombolysis on the evolution of late potentials in the early postinfarction period. ${ }^{15} \mathrm{~A}$ hundred and fifty eight patients were prospectively studied during the first 10 days after acute myocardial infarction. The study population consisted of two non-randomised groups. Ninety three patients had been treated conservatively whereas 65 patients had been treated by intravenous thrombolysis. The incidence of late potentials in the first two days after infarction was not significantly different in patients treated conservatively $(14 \%)$ and those treated by thrombolysis $(11 \cdot 8 \%)$. On days $7-10$ the incidence of late potentials among patients treated by thrombolysis was unchanged; however, it had increased significantly in the conservatively treated group from $11.8 \%$ to $22.5 \%$ ( $p<$ $0 \cdot 01)$. Volosin et al also evaluated the time course of late potentials after myocardial infarction. ${ }^{17}$ They found that in reperfused infarctions development of late potentials was related to the presence of $Q$ waves and was independent of peak creatine kinase concentrations and infarct location. Late potentials sometimes were present only in the early infarction period; they may represent areas of transiently delayed myocardial activation that resolve with infarct healing. ${ }^{17}$

Gang et al reported a similar study in 106 consecutive patients aged $<75$ years who were admitted to hospital with a first acute myocardial infarction. ${ }^{14}$ Forty four patients who had chest pain for less than four hours were treated with alteplase (recombinant tissue plasminogen activator) whereas another 62 patients who either did not qualify for or refused treatment with alteplase were treated conventionally. Thus, they were not a randomised sample of patients with acute myocardial infarction. Age, sex, site, and size of myocardial infarction, extent of coronary artery disease, and left ventricular ejection fraction were similar in both groups. Signal averaging was performed in all patients within 48 hours of admission to the hospital and again in the surviving patients before discharge. Only two $(5 \%)$ of the 44 patients treated with alteplase had late potentials compared with $14(23 \%)$ of 62 patients who were not $(p=0.01)$. The patency of the infarctrelated coronary artery and administration of alteplase were the only independent predictors of the presence of late potentials. 
Preliminary data from Riccio et al on 172 patients in the Gruppo Italiano per lo Studia della Streptochinasi nell' Infarto Miocardico (GISSI-2) study point to similar findings. ${ }^{16}$ Twenty $(16.5 \%)$ of 103 patients treated with streptokinase or alteplase had late potentials compared with $17(28.9 \%)$ of 69 patients who did not receive thrombolytic treatment because of contraindications or late admission to the hospital.

Kersschot et al used programmed ventricular stimulation with three extrastimuli to test for the presence of an arrhythmogenic substrate. ${ }^{18}$ Twenty six days after infarction the induction rate for sustained ventricular arrhythmias in general $(48 \% v 100 \%)$ and uniform ventricular tachycardia $(29 \% v 67 \%)$ in particular was much lower in 21 patients treated with intravenous and intracoronary streptokinase than in 15 control patients. But contradictory results were reported by Treese et al who studied 84 of 127 patients who had been randomised to intravenous and intracoronary thrombolysis with or without transluminal coronary angioplasty. ${ }^{19}$ Group A consisted of 64 patients who showed primary recanalisation of the infarct related vessel with persistent patency at a subsequent follow up angiogram: group $B$ consisted of 20 patients who showed late reopening $(n=5)$ or a closed infarct related vessel $(n=15)$ (caused by late reocclusion in nine). There was no difference between the frequency of ventricular extrasystoles in both groups but repetitive ventricular extrasystoles were more common in group A (21 of 64 patients, 32.8\%) than in group B (2 of 20 patients, $10 \%$; p $<0.05$ ). However, in contrast with the data of Kersschot et al, ${ }^{18}$ there was no difference in the incidence of inducible ventricular tachycardia.

The results of these preliminary studies indicate that successful early reperfusion may prevent the formation of an arrhythmogenic substrate as shown by the presence of late potentials on high resolution electrocardiography or the results of programmed ventricular stimulation. They ${ }^{14-161819}$ raise some important questions:

(a) Why does thrombolytic treatment seem to affect the incidence of ventricular late potentials and the results of programmed ventricular stimulation?

(b) What is the mechanism for the improvement in prognosis after successful thrombolytic treatment? ${ }^{20}$ Is this improvement in prognosis the result of a reduction (albeit small) in infarct size? ${ }^{21} 22$ Or are other mechanisms responsible-such as changes in the electrophysiological milieu?

Thrombolytic treatment aims at opening an occluded coronary artery and thus at reducing infarct size, with the ultimate goal of improving prognosis. Reduction in cardiac mortality was shown in various studies of thrombolytic treatment though this was not a consistent finding. ${ }^{20}$ Outcome was governed by the time from onset of myocardial infarction to thrombolysis, by the patency rate achieved, and possibly by the site of infarction. However, we do not know whether im- provement in prognosis after thrombolytic treatment is due to a reduced mortality from heart failure or from arrhythmic causes. In addition, the mechanism underlying an improvement in prognosis has not yet been adequately examined.

The reduction in infarct size achieved by early thrombolysis is relatively small. Ritchie et al reported a reduction in infarct size (as a percentage of the left ventricle) from $19 \%$ in controls to $15 \%$ in patients treated with streptokinase. ${ }^{21}$ Bassand et al found that the left ventricular ejection fraction was higher $(53 \%)$ in a group treated with anistreplase than in a group that was not given fibrinolytic treatment $(47 \%))^{22}$ The infarct size was reduced by $31 \%$. In the GISSI trial there was no difference in ejection fraction at the predischarge examination in those assigned to streptokinase and those assigned to standard care. ${ }^{24}$ However, patients treated with streptokinase had smaller ventricular volumes and a smaller regional wall motion index than patients given standard treatment. These effects persisted for up to 6 months. Another effect of thrombolytic treatment may be the prevention of aneurysm formation. ${ }^{25}$ This beneficial effect was also seen after late thrombolysis (4-10 hours).

It has been suggested that some of the beneficial effects of alteplase such as improved left ventricular function ${ }^{26}$ or low mortality ${ }^{27}$ may be due to some direct myocardial cellular mechanism that is independent of its ability to lyse intracoronary thrombi. ${ }^{28-33}$ The assumption was that alteplase has a direct protective effect on the myocyte or that it dissolves microthrombi. ${ }^{28}$ These findings are still controversial. However, they may have major implications for the interpretation of the mechanisms of alteplase. ${ }^{33}$

Current data suggest that a patent infarct related coronary vessel reduces the likelihood of ventricular tachycardia even when infarction of the myocardium is developing. Because studies on thrombolytic treatment were not designed to establish the mechanisms of the observed reduction in total mortality, no definite conclusions can be drawn. This is why studies by Gang et al, Eldar et al, and Riccio et al are of great importance because they suggest a potential mechanism for the improvement in prognosis after successful thrombolytic treatment. ${ }^{14-16}$ The correlations between the presence of late potentials and arrhythmic events after myocardial infarction and the low incidence of late potentials in patients with successful early reperfusion suggest that the improvement in prognosis may be due to the prevention of the development of an arrhythmogenic substrate. ${ }^{6} 10$

The factors that govern the genesis of late potentials during the evolution of myocardial infarction are still poorly understood. Gang et al suggested several mechanisms that might lead to the absence of late potentials in patients with successful reperfusion (that is those in whom the infarct related artery was open). ${ }^{14}$ They postulated that the absence of late potentials may be related to reperfusion because it eliminates ischaemia, allows the 
return of various plasma constituents to the ischaemic area, permits a rapid washout of the toxic products of anaerobic metabolism, causes contraction-band necrosis, may increase the amount of haemorrhage within the infarct zone, and may cause the generation of oxygen free radicals. ${ }^{14}$

Late potentials originate from small areas within the myocardial infarction in which surviving muscle cells are interspersed with fibrosis. The duration and the degree of local impairment of blood flow govern the extent of necrosis and subsequent fibrosis which may establish an abnormal electrophysiological milieu. Because thrombolysis aims to restore blood flow to the myocardium as fast as possible, early intervention may influence the genesis of an abnormal electrophysiological substrate in different ways. First, blood flow may be reduced for too long to allow recovery of the myocardium; this leads to total necrosis without the survival of any muscle fibres. In this situation no chronic arrhythmogenic substrate should develop. Secondly, incomplete recovery may lead to regional survival of the myocardium after thrombolysis. This may increase the likelihood of a patchy infarct and thus of an "arrhythmogenic substrate". Thirdly, restoration of blood flow may be achieved early enough to allow complete recovery of the myocardium which should prevent the occurrence of an "arrhythmogenic substrate".

Current data suggest that detection of late potentials by high resolution electrocardiography is a way of assessing the likelihood of arrhythmic events after myocardial infarction. Several studies even suggest that it is a more powerful predictor for ventricular instability than long term electrocardiographic recording. ${ }^{6}$ High resolution electrocardiography seems to be a powerful tool for identifying the presence of an arrhythmogenic substrate after a patient with acute myocardial infarction has been treated by thrombolysis. ${ }^{10}$ Prospective studies using this new technique should help to clarify whether in patients with similar degrees of left ventricular impairment outcome is worse in those with late potentials.

1 Josephson ME, Horowitz LN, Farshidi A, Spielman SR, Michelson EL, Greenspan AM. Sustained ventricular tachycardia: evidence for protected localized reentry. $A m$ $J$ Cardiol 1978;42:416-24.

2 Klein H, Karp RB, Kouchoukos NT, Zorn GL, James TN, Waldo AL. Intraoperative electrophysiologic mapping of the ventricles during sinus rhythm in patients with previous myocardial infarction. Identification of the previous myocardial infarction. Identification of the Circulation 1982;66:847-53.

3 Ostermeyer J, Breithardt G, Kolvenbach R, et al. Intraoperative electrophysiologic mapping during cardiac Intraoperative electrophysiologic mapping during

4 Simson MB. Identification of patients with ventricular tachycardia after myocardial infarction from signals in the terminal QRS complex. Circulation 1981;64:235-42.

5 Breithardt G, Becker R, Seipel L, Abendroth RR, Ostermeyer J. Non-invasive detection of late potentials in man-a new marker for ventricular tachycardia. Eur Heart $J 1981 ; 2: 1-11$.

6 Breithardt G, Borggrefe M. Pathophysiological mechanisms and clinical significance of ventricular late potentials. Eur Heart $J 1986 ; 7: 364-85$.

7 Breithardt G, Borggrefe $M$. Recent advances in the identification of patients at risk of ventricular tachyarrhythmias: role of ventricular late potentials. Circulation 1987;75:1091-6.

8 Gardner PI, Ursell PC, Fenoglio JJ Jr, Wit AL. Electrophysiologic and anatomic basis for fractionated electrograms recorded from healed myocardial infarcts.
Circulation 1985;72:596-611.

9 Richards DA, Blake GJ, Spear JF, Moore EN. Electrophysiologic substrate for ventricular tachycardia: correlation of properties in vivo and in vitro. Circulation 1984;69:369-81.

10 Breithardt G, Borggrefe M, Martinez-Rubio A, Budde T. Pathophysiological mechanisms of ventricular tachyarrhythmias. Eur Heart J 1989;10 (suppl E):9-18.

11 Kienzle MG, Miller J, Fal cone R, Harken A, Josephson ME. Intraoperative endocardial mapping during sinus rhythm: relationship to site of origin of ventricular tachycardia. relationship to site of origin

12 Breithardt G, Borggrefe M, Karbenn U, Abendroth RR, Yeh HL, Seipel L. Prevalence of late potentials in patients with and without ventricular tachycardia: correlation to angiographic findings. Am J Cardiol 1982;49:1932-7.

13 Breithardt G, Borggrefe M, Quantius B, Karbenn U, Seipel L. Ventricular vulnerability assessed by programmed ventricular stimulation in patients with and without late potentials. Circulation 1983;68:275-81.

14 Gang ES, Lew AS, Hong M, Wang FZ, Siebert CA, Peter Th. Decreased incidence of ventricular late potentials after successful thrombolytic therapy for acute myocardial infarction. N Engl J Med 1989;321:712-6.

15 Eldar M, Leor J, Hod H, et al. Effect of thrombolysis on the evolution of late potentials within 10 days of infarction. Br Heart J 1990;63:273-6.

16 Riccio C Cesaro F, Perrotta $R$, Romano $S$, Correale $E$ Corsini G. Early thrombolysis, reperfusion arrhythmias Corsini G. Early thrombolysis, reperfusion arrhythmias and late potentials in acute myocardial
Frontiers of Arrhythmias 1990;6:157-61.

17 Volosin KJ, Beauregard LA, Kurnik BK, Fabiszewski R, Waxman HL. Time course of ventricular late potential development after coronary reperfusion with tissue plasminogen activator [Abstract]. PACE 1989;12 (supp] I):636.

18 Kersschot IE, Brugada P, Ramentol M, et al. Effects of early reperfusion in acute myocardial infarction on arrhythmias induced by programmed stimulation: a prospective, randomized study. J Am Coll Cardiol 1986;7:1234-42.

19 Treese N, Pop T, Erbel R, et al. Outcome of primary coronary recanalization and arrhythmia profile in survivors of acute myocardial infarction. Int $J$ Cardiol 1987;15:19-31.

20 Simoons ML, Vos J, Tijssen JGP, et al. Iong-term benefit of early thrombolytic therapy in patients with acute myocardial infarction: 5 year follow-up of a trial conducmyocardial infarction: 5 year follow-up of a trial conduc-
ted by the Interuniversity Cardiology Institute of the ted by the Interuniversity Cardiology Institute

21 Ritchie JL, Cerqueira M, Maynard C, Davis K, Kennedy JW. Ventricular function and infarct size: The Western Washington Intravenous Streptokinase in Myocardial Infarction Trial. J Am Coll Cardiol 1988;11:689-97.

22 Bassand J-P, Machecourt J, Cassagnes J, et al, for the APSIM Study investigators. Multicenter trial of intravenous anisoylated plasminogen streptokinase activator complex (APSAC) in acute myocardial infarction: effects on infarct size and left ventricular function. $J \mathrm{Am}$ Coll Cardiol 1989;13:988-97.

23 Kennedy JW, Martin GV, Davis KB, et al. The Wester Washington Intravenous Streptokinase in Acute Myocardial Infarction Randomized Trial. Circulation cardial Infarction

24 Marino $P$, Zanolla $L$, Zardini $P$, on behalf of the Gruppo Italiano per lo studia della streptochinasi nell'infarto miocardico (GISSI). Effect of streptokinase on left venmiocardico (GISSI). Effect of streptokinase on left ventricular modelling and function after myocardial infarc-
tion: The GISSI (Gruppo Italiano per lo studia della tion: The GISSI (Gruppo Italiano per lo studia della streptochinasi nell'infarto
Cardiol $1989 ; 14: 1149-58$

25 Hamano Y, Minamino T, Katoh O, et al. Intracoronary thrombolysis limits the complication with left ventricula aneurysm in acute myocardial infarction [Abstract] Circulation 1988;78 (suppl II):502.

26 Guerci AD, Gerstenblith G, Brinker JA, et al. A randomized trial of intravenous tissue plasminogen activator for acute myocardial infarction with subsequent randomisation to elective coronary angioplasty. $N$ Engl J Med 1987;317: 1613-8.

27 Dalen JE, Gore JM, Braunwald E, et al, and the TIM investigators. Six and twelve month follow-up of the Phase I Thrombolysis in Myocardial Infarction (TIMI) Phase I Thrombolysis in Myocardia
trial. Am J Cardiol 1988;62:179-85.

28 Darius H, Yanagisawa A, Brezinski ME, Hock CE, Lefe AM. Beneficial effects of tissue-plasminogen activator in acute myocardial ischaemia in cats. J Am Coll Cardiol 1986;8:125-31.

29 Berger $H$, Oliver $W$, Frangakis CS. Direct myocardial salvage by tissue-type plasminogen activator (t-PA): synergistic activity with superoxide dismutase [Abstract] Circulation 1986;74 (suppl II):II-18.

30 Lefer AM, Mentley R, Jian-Zheng S. Potentiation of myocardial salvage by tissue-plasminogen activator in combination with a thromboxane synthetase inhibitor in ischemic cat myocardium. Circ Res 1988;63:621-7.

31 Kloner RA, Alker K, Campbell C, Figures G, Eisenhauer A, Hale S. Does tissue-type plasminogen activator have direct beneficial effects on the myocardium independent of its ability to lyse intracoronary thrombi? Circulation 1989;79:1125-36

32 Kloner RA, Alker KJ. Effect of streptokinase on intramyocardial hemorrhage, infarct size, and the noreflow phenomenon during coronary reperfusion. refiow phenomenon during

33 Jaffe AS. New mechanism of action for tissue-type plasminogen activator? J Am Coll Cardiol 1986;8:132-3. 


\section{LETTERS TO THE EDITOR}

The British Heart Journal welcomes letters commenting on papers that it has published within the past six months.

- All letters must be typed with double spacing and signed by all authors.

No letter should be more than 600 words.

- In general, no letter should contain more than six references (also typed with double spacing).

Balloon dilatation of tricuspid stenosis caused by carcinoid heart disease

SIR,-Mullins et al's conclusion that balloon dilatation of the tricuspid valve is safe and effective for tricuspid stenosis caused by carcinoid may not be consistent with clinical and haemodynamic data in their patient $(\mathrm{Br}$ Heart $J 1990 ; 63: 249-50)$. They state that the jugular venous pulse showed a prominent systolic wave. This clearly means that tricuspid regurgitation was a clinically important abnormality. This accords with the haemodynamic data because in the basal state the ' $v$ ' wave in the right atrium was $44 \mathrm{mg} \mathrm{Hg}$ whereas the 'a' wave was $24 \mathrm{~mm} \mathrm{Hg}$. They say that the chest $x$ ray showed pulmonary oedema. This is an unusual and unlikely feature of primary tricuspid valve disease, especially when there is no additional left sided disease. Because there was no mention of myocardial or valve disease affecting the left heart I presume that these structures were normal.

Right ventricular hypertension in carcinoid heart disease affecting the right side of the heart is possible only if there is stenosis of the pulmonary valve. The pulmonary valve was normal in this case, so what was the cause of the right ventricular pressure of $52 \mathrm{~mm} \mathrm{Hg}$ ? In addition, a right ventricular diastolic pressure of $18 \mathrm{~mm} \mathrm{Hg}$ is rather surprising in the presence of important tricuspid stenosis without any additional cause for diastolic restriction of the right ventricle.

After dilatation of the tricuspid valve the ' $a$ ' wave in the right atrium remained at $24 \mathrm{~m} \mathrm{Hg}$ whereas the height of the ' $v$ ' wave fell from 44 to $36 \mathrm{~mm} \mathrm{Hg}$. This needs to be explained. Mullins et al claim that the severity of tricuspid regurgitation did not change after dilatation so what was the cause of reduction in the height of the ' $v$ ' wave?

Though after dilatation the mean pressure drop across the tricuspid valve fell from 10.5 to $7.6 \mathrm{~mm} \mathrm{Hg}$ and the valve area increased from 0.9 to $1.4 \mathrm{~cm}^{2}$, are Mullins et al justified in calling this dilatation "effective"? The reduction in the mean pressure drop could have been solely related to the reduction in the height of the ' $v$ ' wave, especially as the height of the ' $a$ ' wave was unchanged. Without knowledge of the cardiac output the effectiveness of dilatation cannot be judged solely on the values of the pressure drops.
Though the area of the tricuspid valve increased, its absolute value of $1.4 \mathrm{~cm}^{2}$ still indicates a critical tricuspid stenosis. ${ }^{1}$

What is more impressive is the fact that despite an ' $a$ ' wave of 24 and a ' $v$ ' wave of $36 \mathrm{~mm} \mathrm{Hg}$ in the right atrium after balloon dilatation the "patient is doing well with reduction of dyspnoea and pulmonary and peripheral oedema". Why did the pulmonary oedema resolve after the release of the tricuspid stenosis? - when it seems logical to expect an increase in pulmonary oedema because of increased flow in the pulmonary circuit

Unless these discrepancies are sorted out I cannot accept that this was predominantly a case of tricuspid stenosis requiring balloon dilatation. Moreover, on the basis of these data alone I believe that it is not correct to call this dilatation effective and recommend it for carcinoid valve disease.

$$
\begin{array}{r}
\text { BHARAT DALVI } \\
\text { Department of Cardiology, } \\
\text { King Edward VII Memorial Hospital, } \\
\text { Parel, } \\
\text { Bombay } 400012,
\end{array}
$$

1 Kitchin A, Turner R. Diagnosis and treatment of tricuspid stenosis. Br Heart J 1964;26: 354-79.

This letter was shown to the authors who reply as follows:

SIR,-We are grateful for Dr Dalvi's interest in the case we presented. He raises three points for debate.

Firstly, was there significant tricuspid stenosis? Tricuspid stenosis was confirmed by a transvalvar gradient of $10.5 \mathrm{~mm} \mathrm{Hg}$ and an orifice area of $0.9 \mathrm{~cm}^{2}$ estimated by Doppler echocardiography. The criticism that the presence of a cardiac catheter across the valve during the haemodynamic study leads to an overestimation of the gradient can be levelled at all gradient estimations. This criticism however, is not valid when the orifice area is estimated by Doppler echocardiography at a different time and the method is not subject to the same measurement constraints.

Secondly, why did the patient have a raised right ventricular diastolic pressure and pulmonary oedema? These abnormalities are not a feature of pure tricuspid stenosis. This elderly woman, presenting with carcinoid, also had poor left ventricular function, the cause of which was not investigated further. We postulated that fluid retention caused by tricuspid stenosis and poor ventricular function was responsible for the pulmonary congestion.

Thirdly, was the tricuspid dilatation successful? We showed a reduced mean gradient and an increase from $0.9 \mathrm{~cm}^{2}$ to $1.4 \mathrm{~cm}^{2}$ in orifice area estimated by Doppler echocardiography. The patient's symptoms of fluid retention and dyspnoea rapidly improved. The increase in tricuspid valve orifice area was maintained on a later echocardiogram.

This patient was terminally ill and in a very poor clinical state. Our aim was to palliate the symptoms associated with her severe tricuspid valve disease. The small improvement in tricuspid valve orifice was sufficient for this purpose.

P MULLINS J HALI L SHAPIRO Regional Cardiac Unit Papworth Hospital, Papworth Everard Cambridge CB3 $8 R E$
Diagnosis of a pseudoaneurysm of the right ventricular outflow tract

SIR,-Sreeram et al reported the diagnosis of a pseudoaneurysm of the right ventricular outflow tract $(1990 ; 63: 129-31)$. Their colour Doppler picture certainly shows clearly the narrow communication between the right ventricle and the pseudoaneurysm.

Those who do not have a colour Doppler machine may be interested to know that a communication such as this can also be detected by contrast echocardiography, as we reported a few years ago.

M BERANT
B Z GARTY
Paediatric Cardiology Unit,
Beilinson Hospital,
Petah Tikva,
Israel

1 Garty BZ, Berant M, Weinhouse E, Levinski L False aneurysm of the right ventricle due to endocarditis in a child. Pediatr Cardio 1987;8:275-7.

This letter was shown to the author, who replies as follows:

SIR,-As Berant and Garty point out in their letter, the use of contrast echocardiography may be a valuable adjunct to the investigation of patients in whom a pseudoaneurysm of the right ventricular outflow tract is suspected.

While contrast echocardiography is a useful alternative non-invasive approach to diagnosis where colour flow mapping is not available, we suggest that colour flow mapping is a more appropriate technique because it can be quickly and easily carried out as part of the ultrasound examination itself. It does not require an intravenous line and administration of a contrast agent. Furthermore, the contrast effect produced can be variable in such patients and thus the results of such studies could be misleading. We expect colour flow mapping will prove to be a more sensitive and specific technique.

GEORGE R SUTHERLAND Department of Cardiology Western General Hospital, Crewe Road

Edinburgh EH4 $2 \mathrm{XU}$

\section{CORRECTION}

Review. Late potentials as predictors of risk after thrombolytic treatment? Günter Breithardt, Martin Borggrefe, Ulrich Karbenn (September 1990 issue, volume 64: pages 174-6) - We regret that an editorial error was introduced into this article. Lines 9, 10, and 11 of the second paragraph on page 174 should have read: There was an inverse relation between the duration of late potentials and the rate of ventricular tachycardia. 